\title{
Expression of mmu-miR-96 in the endometrium during early pregnancy and its regulatory effects on stromal cell apoptosis via $\mathrm{Bcl} 2$
}

\author{
YUAN YANG $^{1 *}$, YI XIE $^{1 *}$, MENGYUN WU $^{1}$, YANQING GENG $^{1}$, \\ RONG $\mathrm{LI}^{2}$, LEI XU ${ }^{3}$, XUEQING LIU ${ }^{1}$ and YONGQUAN PAN ${ }^{3}$ \\ ${ }^{1}$ Laboratory of Reproductive Biology, School of Public Health, Chongqing Medical University; \\ ${ }^{2}$ Department of Obstetrics and Gynecology, The First Affiliated Hospital of Chongqing Medical University; \\ ${ }^{3}$ Laboratory Animal Center, Chongqing Medical University, Chongqing 400016, P.R. China
}

Received December 25, 2015; Accepted December 12, 2016

DOI: $10.3892 / \mathrm{mmr} .2017 .6212$

\begin{abstract}
Decidualization of endometrial stromal cells is an important feature of implantation and pregnancy. The molecular mechanism underlying decidualization remains unclear, particularly regarding the microRNA ( $\mathrm{miRNA} / \mathrm{miR}$ ) regulation of this process. The present study revealed the temporal and spatial distribution of mmu-miR-96 in the mouse uterus during early pregnancy by reverse transcription-quantitative polymerase chain reaction and in situ hybridization. In addition, primary stromal cells were isolated from the mouse uterus and used to explore the role of mmu-miR-96 in decidualization. The results demonstrated that mmu-miR-96 was highly expressed in stromal cells during pregnancy, and was upregulated at implantation sites. In addition, mmu-miR-96 was strongly expressed during decidualization, which indicates that it may serve a role in the decidualization of stromal cells. Based on existing reports, mmu-miR-96 participates in apoptosis; therefore the present study investigated its effects on the apoptosis of primary endometrial stromal cells. The results indicated that overexpression of mmu-miR-96 may induce apoptosis of stromal cells. In further studies regarding the underlying mechanism, the target genes of mmu-miR-96 were screened by bioinformatics analysis, and it was confirmed that B-cell lymphoma 2, an anti-apoptotic gene, was the target of mmu-miR-96, as determined using a reporter gene assay. In conclusion, the present study suggested that mmu-miR-96 participates in the decidualization of endometrial stromal cells in mice, thereby serving a key role in pregnancy.
\end{abstract}

Correspondence to: Mr. Yongquan Pan, Laboratory Animal Center, Chongqing Medical University, 1 Yixueyuan Road, Yuzhong, Chongqing 400016, P.R. China

E-mail: cypyq@126.com

*Contributed equally

Key words: mmu-miR-96, decidualization, Bcl2, apoptosis

\section{Introduction}

Embryonic implantation is a complex reproductive process involving reciprocal interactions between the blastocyst and uterus. Successful embryonic implantation is dependent on implantation of normal embryos, synchronous development of endometrial receptivity, and molecular communication between the embryo and the mother $(1,2)$. The cellular dialogue precisely regulates endometrial decidualization, as well as the proliferation and differentiation of trophoblast cells. During development, the endometrial stromal cells are stimulated by inducing factors, and undergo proliferation and differentiation; a process referred to as decidualization. This process serves a crucial role in the establishment and maintenance of pregnancy (3-5). Recently, microRNA (miRNA/miR) regulation of endometrial gene expression during early pregnancy has received a lot of attention. Chakrabarty et al (6) demonstrated that mRNA expression of cyclooxygenase-2, which is critical for embryonic implantation, was post-transcriptionally regulated by mmu-miR-101a and mmu-miR-199a. Furthermore, Hu et al (7) demonstrated differential expression of miRNAs in the mouse uterus between implantation sites (IS) and inter-implantation sites (IIS) by miRNA microarray. Shen et al (8) reported that mmu-miR-200a has an important role in embryonic implantation and that phosphatase and tensin homolog is the target gene of mmu-miR-200a. However, in recent years, few studies have investigated the involvement of miRNAs in the regulation of decidualization.

miRNAs are a class of non-coding small RNA molecules, 18-24 nucleotides in length, which cause either the degradation of target mRNA, or translational inhibition through target mRNA-specific base pairing (9). They affect various biological processes, including development, cell growth, differentiation, apoptosis and maintenance of tissue identity (10). A previous study investigated the dynamic alterations in miRNA and mRNA levels during the pre-receptivity, receptivity and implantation phases, which reflect the mechanism by which miRNAs regulate their target mRNAs. Mmu-miR-96 and mmu-miR-200 were revealed to act as hub miRNAs, and were 
verified to share the target gene B-cell lymphoma 2 (Bcl2), and to exert synergistic regulation (11).

Previous in house miRNA microarray results demonstrated that mouse uterine expression of mmu-miR-96 was upregulated at IS on day five of pregnancy compared with at IIS, indicating that it may participate in the regulation of implantation (11). Mmu-miR-96, which maps to chromosomal region 17 , is one of the members of the miR-183 family, other members of which include microRNA-183 and microRNA-182, and has recently been found to have a role in cancer. Its expression is upregulated in various tumors, including bladder cancer $(12,13)$, lung cancer $(14)$, breast cancer $(15)$, endometrioid carcinomas (16) and liver cancer (17). A previous study identified that miR-96 promoted suppression of forkhead box protein $\mathrm{O} 1$ (FOXO1) and may serve a key role in transitional cell carcinoma tumorigenesis by avoiding cell apoptosis (18). Furthermore, the upregulation of miR-96 has been reported to induce downregulation of the transcription factors FOXO3a and FOXO1, and thus promote cell proliferation in human breast cancer $(15,19)$. It has also been revealed that in non-small cell lung cancer-derived cell lines, downregulation of miR-96 inhibits proliferative and invasive capacities, and promotes apoptosis (20). Therefore, the present study hypothesized that mmu-miR-96 may serve a role in decidualization by regulating the proliferation and apoptosis of endometrial stromal cells. This study aimed to investigate the target gene of mmu-miR-96. The results revealed the expression pattern and function of mmu-miR-96 in the endometrium during early pregnancy in mice. In addition, the anti-apoptotic protein $\mathrm{Bcl} 2$ was identified as the target gene of mmu-miR-96 in the endometrium.

\section{Materials and methods}

Animals and tissue preparation. A total of 52 female and 13 male Kunming mice (age, 6-8 weeks; weight, 25-30 g) were provided by the Laboratory Animal Center of Chongqing Medical University, [Chongqing, China; Certificate No.: SCXK (YU) 20070001]. The mice were housed in the Chongqing Medical University Animal Care Facility with ad libitum access to food and water under a $14 \mathrm{~h} \mathrm{light} / 10 \mathrm{~h}$ dark cycle, at constant temperature $\left(22 \pm 2^{\circ} \mathrm{C}\right)$ and humidity $(50 \%)$. Ethical approval for this study was provided by the Ethics Committee of Chongqing Medical University [Certification No: SCXK (YU) 20110016]. Female mice were mated with fertile or vasectomized males of the same strain to induce pregnancy or pseudopregnancy, respectively. The presence of a vaginal plug was regarded as the first day of pregnancy (D1). The mice were sacrificed by cervical dislocation and the tissue samples of mice were obtained on pregnancy day 1, 4, 5,6 and 7. IS and IIS tissues were collected according to a previous study (21). The artificially induced decidualization mouse model was generated according to standard criteria. Briefly, on day 4 of pseudopregnancy, $25 \mu \mathrm{l}$ corn oil was infused into one uterine horn to induce artificial decidualization and another horn without any infusion served as the control. On day 8 of pseudopregnancy the mice were sacrificed by cervical dislocation.

In situ hybridization. The mmu-miR-96-specific probe and the negative control (scramble) were purchased from Exiqon A/S
(Vedbaek, Denmark). Probe sequence: AAGCAAAAATGT GCTAGTGCCAAA. An in situ hybridization kit (Dingguo Biotechnology Co. Ltd., Beijing, China) was used for hybridization according to the manufacturer's protocol. Briefly, frozen endometrial tissues were sectioned $(10 \mu \mathrm{m})$ and fixed with $4 \%$ paraformaldehyde at room temperature for $10 \mathrm{~min}$. The uterine sections were treated with protease $\mathrm{K}$ at $37^{\circ} \mathrm{C}$ for 5 min, and then incubated with prehybridization solution for $4 \mathrm{~h}$ at $50^{\circ} \mathrm{C}$, followed by incubation with hybridization solution including probes $(40 \mathrm{mmol} / \mathrm{l})$ overnight at $50^{\circ} \mathrm{C}$. After washing with standard saline citrate, sections were incubated with bovine serum albumin (1:100 dilution) at $37^{\circ} \mathrm{C}$ for $1 \mathrm{~h}$, and then with alkaline phosphatase-labeled goat anti-rabbit immunoglobulin G (1:100 dilution) for $1 \mathrm{~h}$. Nitro-blue tetrazolium chloride/5-bromo-4-chloro-3'-indolylphosphate was employed to indicate a positive signal and the nuclei were stained with Nuclear Fast Red. All slides were viewed directly under a microscope (BX43; Olympus Corporation, Tokyo, Japan).

Cell culture and treatment. Primary cells were isolated from the uteri of mice as previously described $(22,23)$. The mice were sacrificed on day 4 (stromal cells) or day 8 (decidual cells) of pregnancy by cervical dislocation, and the uteri were split longitudinally. After washing with D-Hank's Balanced Salt Solution (HBSS) (Boster Systems, Inc., Pleasanton, CA, USA), uterine tissues were cut into small pieces and treated with $7.5 \mathrm{ml} \mathrm{HBSS}$ containing 1\% (w/v) trypsin (Boster Systems, Inc.) and $6 \mathrm{mg} / \mathrm{ml}$ dispase (Roche Diagnostics, Indianapolis, IN, USA). The tissues were rinsed 3 times with HBSS and incubated in $2 \mathrm{ml}$ HBSS containing $0.5 \mathrm{mg} / \mathrm{ml}$ collagenase I (Invitrogen; Thermo Fisher Scientific, Inc.) at $37^{\circ} \mathrm{C}$ for $30 \mathrm{~min}$. The suspension was purified through a $70-\mu \mathrm{m}$ nylon filter and centrifuged at $1,500 \times \mathrm{g}$ for $5 \mathrm{~min}$. The cells were seeded in $50 \mathrm{ml}$ culture flasks and cultured in phenol red-free culture medium (DMEM/Ham's F-12; 1:1; Sigma-Aldrich; Merck Millipore, Darmstadt, Germany) containing 10\% charcoal-stripped fetal bovine serum (FBS) (Sigma-Aldrich; Merck Millipore). The cells were transfected with miR-96 mimic (5'-UUUGGCACUAGCACAUUUUUGCU-3' 5'AGC AAAAAUGUGCUAGUGCCAAA-3') or a negative control (5'UUUGUACUACACAAAAAGUACUG3' 5'CAGUAC UUUUGUGUAGUACAAA3') (Guangzhou RiboBio Co. Ltd., Guangzhou, China) using Lipofectamine 2000 (Invitrogen; Thermo Fisher Scientific, Inc.). The medium was replaced with fresh DMEM/F12 medium (supplemented with $10 \%$ FBS) after transfection for 4 to $6 \mathrm{~h}$, and then collected $48 \mathrm{~h}$ later.

In vitro decidualization. Decidualization was performed as described previously $(24,25)$, with modification. Briefly, endometrial stromal cells isolated from the uteri of mice on day 4 of pregnancy were treated with $10 \mathrm{nmol} / \mathrm{l}$ estradiol-17 $\beta$ (Sigma-Aldrich; Merck Millipore) and $1 \mu \mathrm{mol} / \mathrm{l}$ progesterone (Sigma-Aldrich; Merck Millipore) for $96 \mathrm{~h}$, whereas endometrial stromal cells not treated with E2P4 served as the control group. Culture medium was changed each day.

Reverse transcription-quantitative polymerase chain reaction $(R T-q P C R)$. Total RNA was extracted from mouse endometrial tissues or cultured cells using TRIzol reagent 
(Invitrogen; Thermo Fisher Scientific, Inc., Waltham, MA, USA) according to the manufacturer's protocol. RT of cDNA was conducted using the miScript II Reverse Transcription kit with miScript HiSpec Buffer (Qiagen, Inc., Valencia, CA, USA,). Briefly, RNA was mixed with miScript HiSpec Buffer, RNAse-free water and miscript Reverse Transcriptase Mix, and was incubated at $37^{\circ} \mathrm{C}$ for $60 \mathrm{~min}$ and $95^{\circ} \mathrm{C}$ for $5 \mathrm{~min}$. qPCR was conducted with the miScript SYBR-Green Real Time PCR kit (Qiagen, Inc.) for miRNA detection and SYBR Premix Ex Taq. The specific primers for mmu-miR-96, U6, $\mathrm{Bcl} 2$, decidual/trophoblast prolactin-related protein (dtPRP) and $\beta$-actin were synthesized by Sangon Biotech Co., Ltd. (Shanghai, China) (Table I). The qPCR master mix (15 $\mu \mathrm{l})$ contained 7.5 $\mu \mathrm{l}$ SYBR Premix Ex Taq, $0.6 \mu \mathrm{l}$ primers, $1.2 \mu \mathrm{l}$ cDNA and $5.1 \mu \mathrm{l}$ diethylpyrocarbonate-treated $\mathrm{H}_{2} \mathrm{O}$. The thermocycling conditions were as follows: Initial denaturation at $95^{\circ} \mathrm{C}$ for $30 \mathrm{sec} ; 40$ cycles at $95^{\circ} \mathrm{C}$ for $5 \mathrm{sec}$ (denaturation) and $60^{\circ} \mathrm{C}$ for $30 \mathrm{sec}$, followed by $72^{\circ} \mathrm{C}$ for $5 \mathrm{sec}$. Experiments were performed in triplicate. Data obtained from qPCR were analyzed using the $2^{-\Delta \Delta \mathrm{Cq}}$ method (26).

Flow cytometric analysis. The stromal cells transfected with mmu-miR-96 mimics and negative controls were collected. At $48 \mathrm{~h}$ post-transfection, the cells were harvested and washed three times with PBS. Flow cytometry was used to analyze cell cycle progression and apoptosis according to a previous report (27). The experiment was repeated three times.

Western blotting. Cells were harvested for protein extraction using cell lysis buffer (Beyotime Institute of Biotechnology, Haimen, China). The protein concentration was determined using the Bicinchoninic Acid Protein Assay kit (Beyotime Institute of Biotechnology) according to the manufacturer's protocol. Total proteins $(50 \mu \mathrm{g})$ were separated by $10 \%$ sodium dodecyl sulfate-polyacrylamide gel electrophoresis and transferred to polyvinylidene difluoride membranes (EMD Millipore, Billerica, MA, USA). The membranes were blocked with $5 \%$ nonfat milk in PBS with $0.1 \%$ Tween-20 (PBST) for $1 \mathrm{~h}$ at room temperature. Immunoblotting was performed by incubating the membranes in 5\% milk-PBST overnight at $4^{\circ} \mathrm{C}$ with rabbit monoclonal anti-Bcl2 (1:600; cat. no. sc-509; Santa Cruz, Biotechnology, Inc., Dallas, TX, USA). After washing three times in PBST, the membranes were incubated for $1 \mathrm{~h}$ with goat anti-rabbit immunoglobulin G antibody (1:1,000; cat. no. BA1055; Wuhan Boster Biological Technology Co., Ltd., Wuhan, China). Bcl2 expression was normalized to $\beta$-actin $(1: 1,000$; cat. no. A5441; Sigma-Aldrich; Merck Millipore). The immunoreactive bands were visualized using ChemiDoc ${ }^{\mathrm{TM}}$ XRS+ (Bio-Rad Laboratories, Inc., Hercules, CA, USA) and chemiluminescent reagents (cat. no. WBKLS0500; EMD Millipore). The image collection and densitometric analysis was performed using Quantity One analysis software, version 4.6.2 (Bio-Rad Laboratories, Inc., Hercules, CA, USA). Protein expression levels were normalized against $\beta$-actin.

Fluorescence reporter vector analysis. Fluorescence reporter vector analysis, including generation of the mutated sequence of Bcl2, was conducted with assistance from Tianjin Saierbio
Table I. Primers used for reverse transcription-quantitative polymerase chain reaction.

\begin{tabular}{|c|c|c|}
\hline Gene & Primer & Sequence $\left(5^{\prime}-3^{\prime}\right)$ \\
\hline $\begin{array}{l}\text { Mmu- } \\
\text { miR-96 }\end{array}$ & RT primer & $\begin{array}{l}\text { GTCGTATCCAGTGCAGGGTCCGA } \\
\text { GGTATTCGCACTGGATACGACAG } \\
\text { CAAA }\end{array}$ \\
\hline & $\begin{array}{l}\text { Forward } \\
\text { Reverse }\end{array}$ & $\begin{array}{l}\text { TTTGGCACTAGCACATTTTTG } \\
\text { GTGCAGGGTCCGAGGT }\end{array}$ \\
\hline U6 & $\begin{array}{l}\text { RT primer } \\
\text { Forward }\end{array}$ & $\begin{array}{l}\text { CGCTTCACGAATTTGCGTGTCAT } \\
\text { GCTTCGGCAGCACATATACTAAA } \\
\text { AT } \\
\text { CGCTTCACGAATTTGCGTGTCAT }\end{array}$ \\
\hline $\mathrm{Bcl} 2$ & $\begin{array}{l}\text { Forward } \\
\text { Reverse }\end{array}$ & $\begin{array}{l}\text { CGATTGTGGCAGTCCCTTA } \\
\text { CAGGATGAAGTGCTCAGGTG }\end{array}$ \\
\hline dtPRP & $\begin{array}{l}\text { Forward } \\
\text { Reverse }\end{array}$ & $\begin{array}{l}\text { AGCCAGAAATCACTGCCACT } \\
\text { TGATCCATGCACCCATAAAA }\end{array}$ \\
\hline$\beta$-actin & $\begin{array}{l}\text { Forward } \\
\text { Reverse }\end{array}$ & $\begin{array}{l}\text { TCGTGCGTGACATCAAAGAC } \\
\text { CAAGAAGGAA GGCTGGAAAA }\end{array}$ \\
\hline
\end{tabular}

miR-96, microRNA-96; Bcl2, B-cell lymphoma 2; dtPRP, decidual/trophoblast prolactin-related protein; RT, reverse transcription.

Technology Incorporation (Tianjin, China). Enhanced green fluorescent protein (EGFP) cDNA was removed from the pEGFP-N2 vector (Clontech Laboratories Inc., Mountainview, CA, USA) using restriction enzymes and subcloned into the pcDNA3.1 vector (Invitrogen; Thermo Fisher Scientific, Co. Ltd.). The 3'-untranslated region fragments from $\mathrm{Bcl} 2$ containing the predicted mmu-miR-96 binding site were cloned into pcDNA3.1/EGFP constructs at the BamHI and EcoRI sites. Four types of vector were constructed in the present study: i) pcDNA3/EGFP/Bcl2; ii) pcDNA3.1(+), iii) pcDNA3.1/pri-miR-96 and iv) mutant vector $\mathrm{Mu}-\mathrm{pcDNA} 3 / \mathrm{EGFP} / \mathrm{Bcl} 2$. Six groups were subsequently established: i) pcDNA3/EGFP/Bcl2; ii) pcDNA3/EGFP/Bcl2 + pcDNA3.1 (+); iii) pcDNA3/EGFP/Bcl2 + pri-96; iv) $\mathrm{Mu}-$ pcDNA3/EGFP/Bcl2; v) Mu-pcDNA3/EGFP/Bcl2 + pcDNA3.1 (+); and vi) Mu-pcDNA3/EGFP/Bcl2 + pri-96. The Mu-pcDNA3/EGFP/Bcl2 plasmid included a mutated sequence of $\mathrm{Bcl} 2$ that was predicted to interact with mmu-miR-96. The mouse uterine stromal cells were co-transfected in 24-well plates with $0.5 \mathrm{mg}$ EGFP reporter vector and $0.1 \mathrm{mg}$ control vector containing pDsRed-C1 (Invitrogen; Thermo Fisher Scientific, Inc.). EGFP and red fluorescent protein activities were measured using a fluorospectrometer. Plasmids containing the EGFP sequence coded green fluorescence. Measuring the fluorescence intensity can be used to measure the activity of EGFP.

Digital gene expression (DGE) library preparation and sequencing. Total RNA isolated from each sample was used for DGE library preparation. The DGE libraries were established as described previously (28). Briefly, mRNA was reverse transcribed to cDNA, ligated to sequencing adapters, and the products were purified and enriched with PCR to create 
A

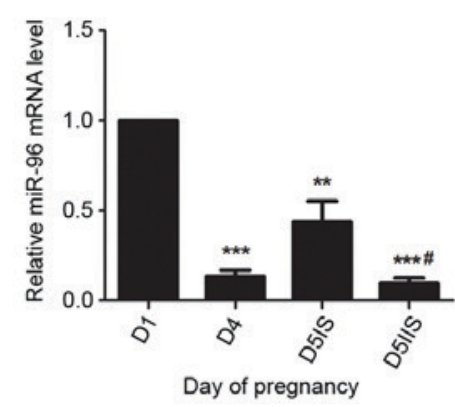

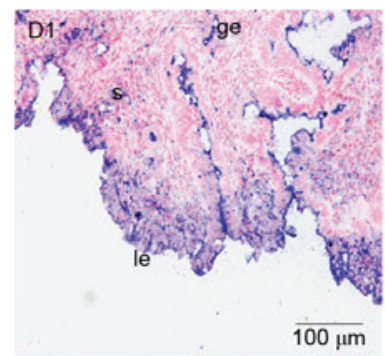
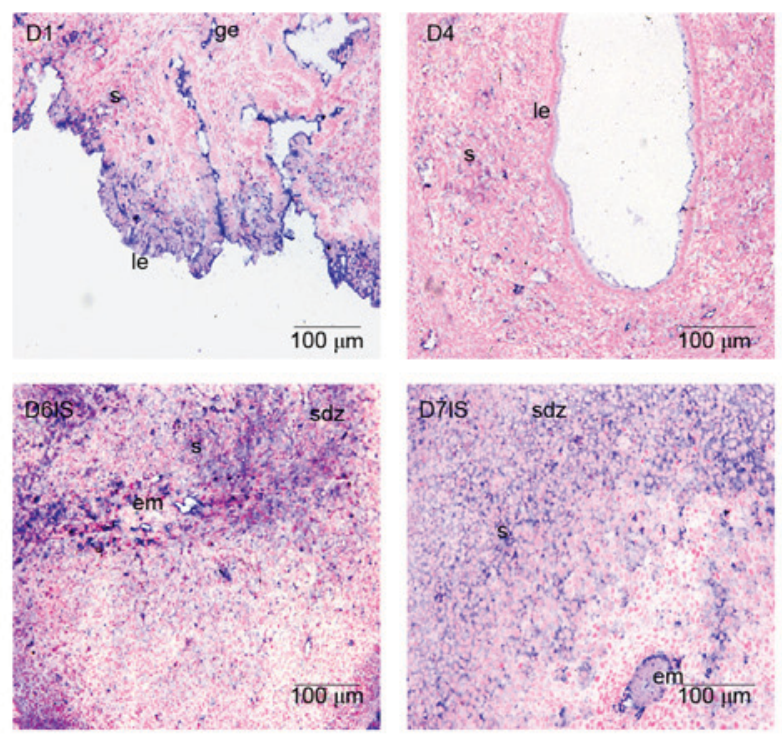
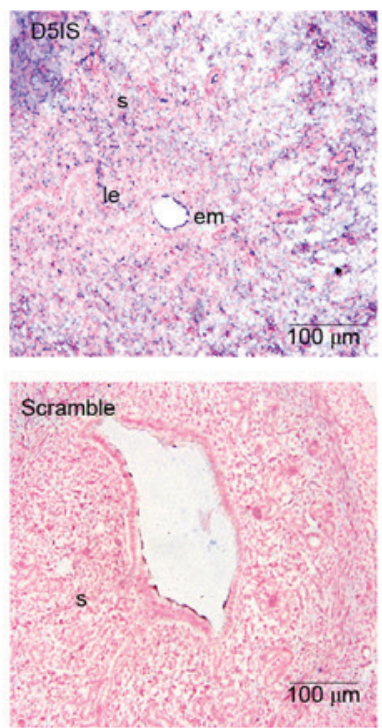

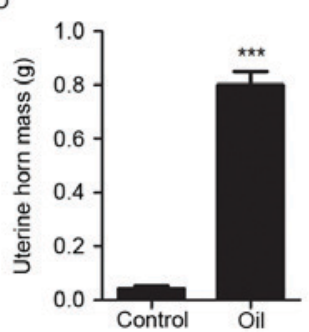

E

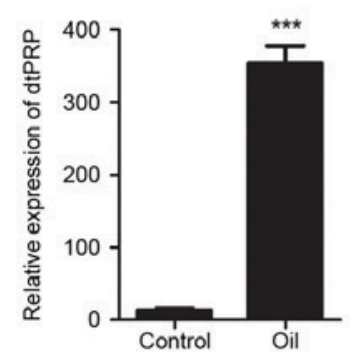

$\mathrm{F}$

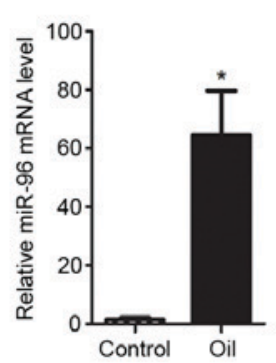

Figure 1. Expression of mmu-miR-96 in mouse endometrium. (A) mRNA expression levels of mmu-miR-96, as detected by RT-qPCR $\left({ }^{* *} \mathrm{P}<0.01,{ }^{* * *} \mathrm{P}<0.001\right.$, vs. $\mathrm{D} 1 ;{ }^{*} \mathrm{P}<0.05$, vs. D5IS). (B) Location of mmu-miR-96 detected by in situ hybridization. Blue represents positive signals. Scrambled represents a negative control. Scale bar, $100 \mu \mathrm{m}$. (C) Typical uterine appearance of artificial decidualization. (D) Statistical analysis of uterine horn weight $\left.{ }^{* * *} \mathrm{P}<0.001\right)$. (E) Expression of dtPRP detected by RT-qPCR ( ${ }^{* * *}$ P<0.001). (F) Expression of mmu-miR-96 between the infused (oil) and non-infused (control) uterine horns. RT-qPCR, reverse transcription-quantitative polymerase chain reaction; miR-96, microRNA-96; IS, implantation site; IIS, inter-implantation site; dtPRP, decidual/trophoblast prolactin-related protein; le, luminal epithelium; ge, gland epithelium; s, stromal; em, embryo; sdz, secondary decidual zone.

the final cDNA libraries. Subsequently, the libraries were sequenced using the Illumina GAII system (Illumina, San Diego, CA, USA). Statistical analyses were performed, and the significantly differentially expressed genes were determined at a threshold false discovery rate (FDR) and absolute value of the $\log 2$ ratio. DGE data analysis was conducted by BGI Tech Solutions Co., Ltd. (Shenzhen, China).

Statistical analysis. The data were analyzed using SPSS13.0 (SPSS Inc., Chicago, IL, USA). Student's $t$-test was used to analyze differences between two groups, whereas the differences between numerous groups were detected using one-way analysis of variance followed by Student-Newman-Keuls test. $\mathrm{P}<0.05$ was considered to indicate a statistically significant difference. Data were expressed as the mean \pm standard error of the mean of experiments repeated at least three times.

\section{Results}

Differential expression of mmu-miR-96 in mouse uterus during early pregnancy. The present study detected the temporal and spatial distribution of uterine mmu-miR-96 during early pregnancy. The results of the qPCR analysis were consistent with the miRNA array (data not shown). On day 5 of pregnancy, the expression levels of mmu-miR-96 were much higher at the IS compared with the IIS (Fig. 1A). In situ hybridization demonstrated that mmu-miR-96 was mainly located in the luminal epithelia on day 1 (Fig. 1B). Weak positive signals were observed in the stromal cells on day 4, whereas its expression increased in stromal cells and in the embryo on day 5 of pregnancy. Mmu-miR-96 was widely expressed in the second decidual zone (SDZ) on day 6, which was further expanded on day 7 (Fig. 1B). To explore the expression of mmu-miR-96 during decidualization, whilst avoiding influence from the blastocyst, artificial in vivo and in vitro models of decidualization using stromal cells were employed. Compared with the control horn, the oil-infused horn presented a robust deciduoma (Fig. 1C), and the weight of the deciduoma was greater than that of the control horn (Fig. 1D). Furthermore, expression of the decidualization marker dtPRP was increased in the infused horn (Fig. 1E), which confirmed the model was successfully established. Finally, mmu-miR-96 expression was much higher in the deciduoma, as compared with the control horn (Fig. 1F). These data indicated that mmu-miR-96 may participate in the transformation of stromal cells into decidual cells, or in the regulation of decidual cells to support the subsequent development of the fetus. 

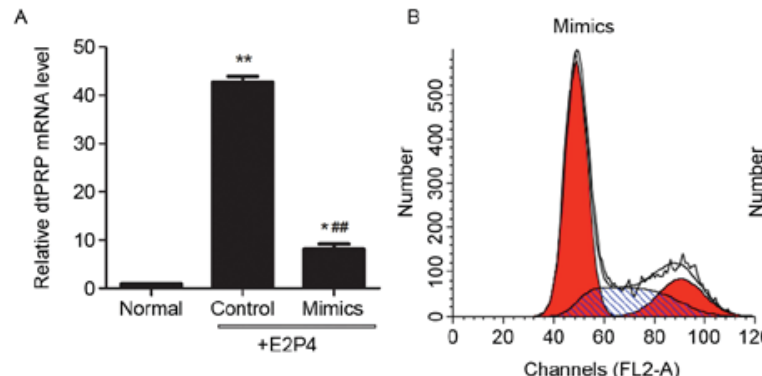

D
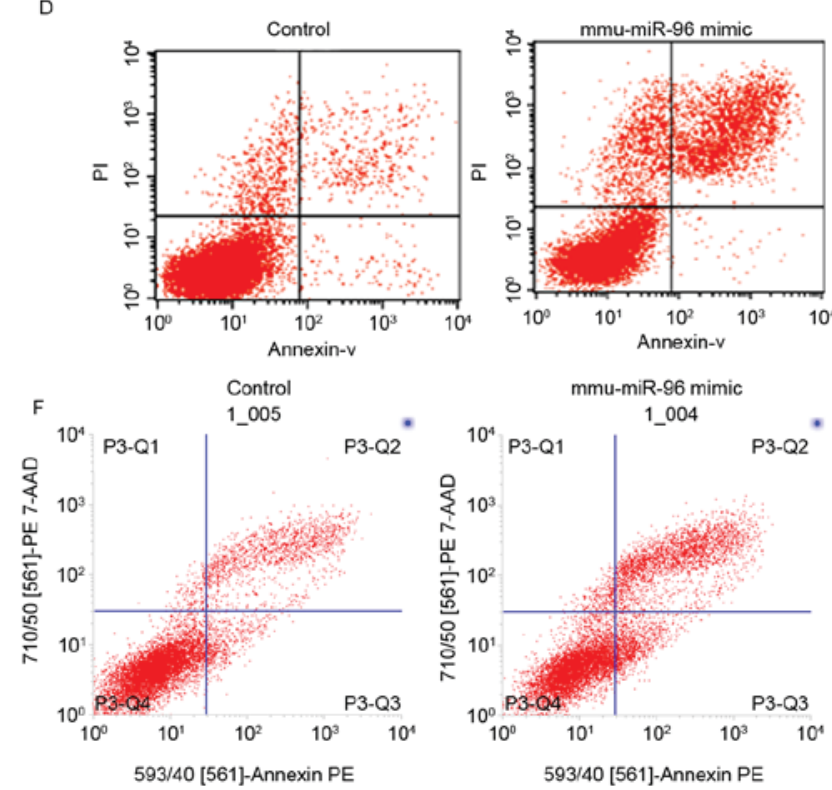
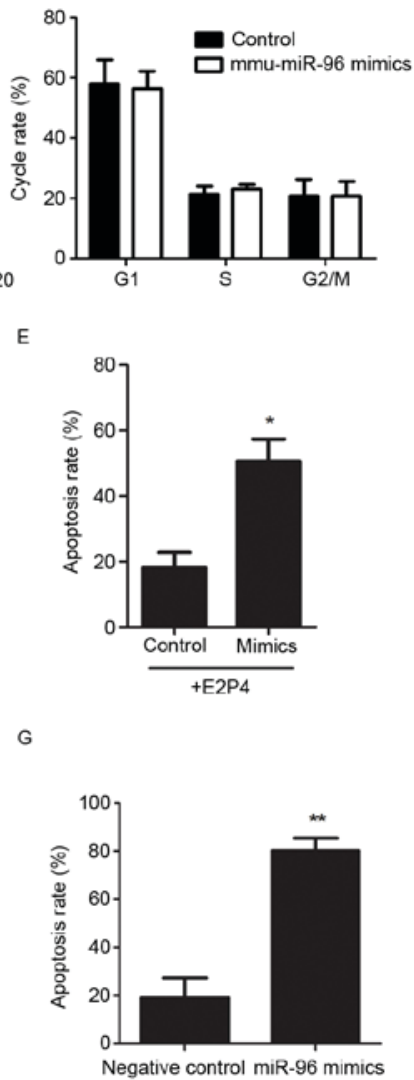

Figure 2. Effects of mmu-miR-96 on stromal cells and decidual cells. (A) Expression of dtPRP in cells transfected with mimics or controls, following hormone treatment with E2P4 detected by RT-qPCR ( ${ }^{* *} \mathrm{P}<0.01$ vs. normal untransfected cells; ${ }^{\# \#} \mathrm{P}<0.01$ vs. control). (B) Cell cycle analysis of stromal cells detected by flow cytometry. (C) Statistical analysis of cell cycle rate. (D) Apoptotic analysis of stromal cells detected by flow cytometry. (E) Statistical analysis of the rate of apoptosis $\left({ }^{*} \mathrm{P}<0.05\right)$. (F) Apoptotic analysis of primary decidual cells detected by flow cytometry. (G) Statistical analysis of the rate of apoptosis $\left({ }^{* *} \mathrm{P}<0.01\right)$. RT-qPCR, reverse transcription-quantitative polymerase chain reaction; miR-96, microRNA-96; E2P4, estradiol-17/progesterone; dtPRP, decidual/trophoblast prolactin-related protein.

Effects of mmu-miR-96 on endometrial decidualization. To identify the role of mmu-miR-96 in the endometrium during early pregnancy, further functional experiments were conducted in primary endometrial stromal cells. Compared with the control group, the mRNA expression levels of dtPRP in the hormone treatment group (E2P4) increased significantly, whereas expression of dtPRP decreased following transfection with the mmu-miR-96 mimic (Fig. 2A). Furthermore, the effects of mmu-miR-96 on the proliferation and apoptosis of stromal cells were investigated. Flow cytometric analysis indicated that mmu-miR-96 expression in stromal cells did not result in changes to the cell cycle (Fig. 2B and C), whereas the rate of apoptosis was markedly increased following overexpression of mmu-miR-96 (Fig. 2D and E). These data indicated that upregulation of mmu-miR-96 in the deciduoma may be involved in the regulation of decidual cells to maintain pregnancy. To address this, primary decidual cells were transfected with mmu-miR-96 mimics, and then the apoptotic rate was observed. Consistently, excessive mmu-miR-96 induced apoptosis in decidual cells (Fig. 2F and G). These data indicated that overexpression of mmu-miR-96 may inhibit the transformation of stromal cells into decidual cells by inducing apoptosis, and that mmu-miR-96 may serve a role in the apoptosis of decidual cells to support the subsequent development of the fetus.

Identification of the target gene of mmu-miR-96. To further determine the molecular mechanism by which mmu-miR-96 induces apoptosis, the target genes of mmu-miR-96 were predicted using TargetScan (http://www.targetscan. org/vert_71/), miRGen (http://carolina.imis.athena-innovation. gr/diana_tools/web/index.php?r=mirgenv3\%2Findex) and Pictar (www.pictar.org). Three predicted target genes, namely $\mathrm{Bcl} 2, \mathrm{Bcl} 212$, and $\mathrm{Bcl} 213$, which are associated with cell apoptosis, were of interest. From this information, combined with our recent gene expression data (data not shown) on day 5 endometrium by DGE analysis, the present study focused on $\mathrm{Bcl} 2$. DGE analysis demonstrated differential endometrial expression of $\mathrm{Bcl} 2$ between the IS and the IIS (Table II and Fig. 3A), whereas there was no significant difference in Bcl2112 and $\mathrm{Bcl} 2113$ expression (data not shown). To verify expression of $\mathrm{Bcl} 2$, the levels of $\mathrm{Bcl} 2$ protein in the endometrium on days 1, 4, 5, 6 and 7 of pregnancy were detected by western blotting. As shown in Fig. 3B, Bcl 2 expression was lowest on day 1 and increased thereafter. On day 5, the levels of $\mathrm{Bcl} 2$ protein were higher at IIS compared with at IS (Fig. 3B and C). This finding suggested that the expression of mmu-miR-96 is inversely 
Table II. Levels of mmu-miR-96 and Bcl2 mRNA in endometrium on day 5 detected by digital gene expression tag profiling.

\begin{tabular}{llccr}
\hline & \multicolumn{4}{c}{ Relative expression on day 5} \\
\cline { 2 - 5 } Gene & \multicolumn{1}{c}{ IS } & IIS & log2 Ratio (D5IS/D5IIS) & P-value \\
\hline Mmu-miR-96 & 21.6031 & 3.0448 & 2.82681898 & $2.15 \mathrm{E}-37$ \\
Bc12 & 30.05 & 89.4 & -1.57290984047213 & $7.39 \mathrm{E}-33$ \\
\hline
\end{tabular}

miR-96, microRNA-96; Bcl2, B-cell lymphoma 2; IS, implantation sites; IIS, inter-implantation sites; D5, day 5.

\begin{tabular}{l|ll} 
& \multicolumn{2}{|c}{$\begin{array}{c}\text { Predicted consequential pairing of target regic } \\
\text { and miRNA (bottom) }\end{array}$} \\
\hline $\begin{array}{l}\text { Position 200-206 of BCL2 3' UTR } \\
\text { mmu-miR-96-5p }\end{array}$ & $5^{\prime}$ & $\begin{array}{l}\text {..GAAUCAGCUAUUUACUGCCAAAG... } \\
\text { IIII } \\
\text { M' }\end{array}$ \\
\hline
\end{tabular}

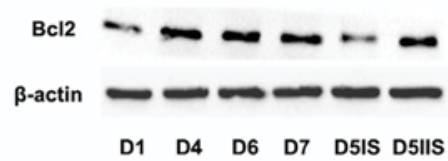

D

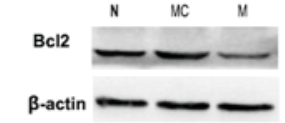

E

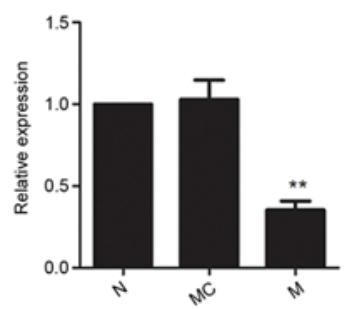

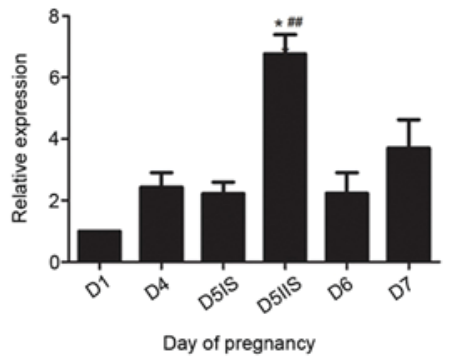

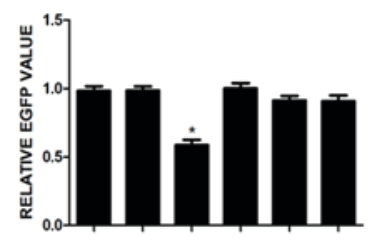

$\begin{array}{lllllll}\operatorname{miR}-96 & - & - & + & - & - & + \\ \text { pcDNA3.1(+) } & - & + & - & - & + & - \\ \text { pcDNA3/EGFP/BCI2 } & + & + & + & - & - & - \\ \text { MU-pCDNA/EGFP/Bcl2 } & - & - & + & + & +\end{array}$

Figure 3. Bcl2 is a target gene of mmu-miR-96. (A) Predicted binding sites between mmu-miR-96 and 3'-UTR of Bcl2 retrieved by TargetScan. (B) Protein levels of Bcl2 in mouse endometrium detected by western blot analysis. $\beta$-actin was used as a loading control. (C) Relative protein expression levels of Bcl2 in mouse endometrium, from the western blot analysis shown in $\mathrm{B}\left({ }^{\prime} \mathrm{P}<0.05\right.$ vs. $\mathrm{D} 1$; ${ }^{\# \#} \mathrm{P}<0.01$ vs. D5IS). (D) Expression of Bcl2 in stromal cells post-transfection with mmu-miR-96 mimics. (E) Quantification of relative expression ( $\left.{ }^{* *} \mathrm{P}<0.01\right)$. (F) EGFP fluorescence reporter vector analysis ( $\left.\mathrm{P}<0.05\right)$. UTR, untranslated region; Bcl2, B-cell lymphoma 2; IS, implantation site; IIS, inter-implantation site; N, untreated cells; MC, negative control of mimics; M, mimics; EGFP, enhanced green fluorescent protein.

correlated with Bcl2 protein levels. Levels of Bcl2 expression were also assessed in the mmu-miR-96 mimic-transfected endometrial stromal cells. The results revealed that $\mathrm{Bcl} 2$ protein levels were reduced when mmu-miR-96 was overexpressed in stromal cells (Fig. 3D and E). Finally, a fluorescent reporter gene assay was performed (Fig. 3F). The expression levels of EGFP were lowest in pcDNA3/EGFP/Bcl2 and mmu-miR-96 transfected cells, indicating that mmu-miR-96 significantly reduced EGFP expression compared with the control, whereas the EGFP expression remained unaffected in the Mu-pcDNA3/EGFP/Bcl2 transfected cells. This result confirmed that mmu-miR-96 targets the 3'-UTR of $\mathrm{Bcl} 2$ mRNA in stromal cells. These results suggested that mmu-miR-96 regulates expression of Bcl2 in stromal cells and $\mathrm{Bcl} 2$ is a target gene of mmu-miR-96. The data indicated that
mmu-miR-96 may participate in decidualization by regulating endogenous Bcl2.

\section{Discussion}

Following implantation of the blastocyst, the endometrium thickens and the stromal cells differentiate; their morphological transformation from fibroblast cells to larger, multinuclear cells is associated with increasing proliferation and degradation, and this series of changes in the endometrium is called the decidual reaction $(29,30)$. A previous study provided the miRNA signature of human endometrial stromal cells (hESC) during the decidualization process in vitro and analyzed the role of the enzyme Dicer during this process (31). Research also illustrated that miR-181a 
serves an important role in the decidualization of human endometrial stromal cells by inhibiting kruppel-like factor 12 (KLF12) (32). These studies suggested that miRNAs participate in the regulation of decidualization. The present study demonstrated that mmu-miR-96 is also involved in decidualization by regulating cell apoptosis, and potentially affecting embryo implantation.

miR-96 is generally considered to be an oncogene due to its ability to promote cell proliferation and inhibit cell apoptosis. The present study revealed that mmu-miR-96 expression at IS was higher than at IIS, and was mainly located in stromal cells. Mmu-miR-96 was widely expressed in the SDZ on day 6 , which was further expanded on day 7. The rate of apoptosis was markedly increased following overexpression of mmu-miR-96; excessive mmu-miR-96 was able to induce apoptosis of decidual cells. These results suggested that it may be involved in the decidualization of stromal cells or in the maintenance of decidual cells.

Endometrial stromal cells undergo extensive proliferation prior to implantation, followed by differentiation and transformation into decidual cells following implantation. It has previously been reported that miR-96 regulates FOXO1 expression in decidualized hESCs (31). To further investigate whether mmu-miR-96 is associated with endometrial decidualization, artificial decidualization was performed in vivo and in vitro, and the results indicated that mmu-miR-96 expression was increased in decidual cells compared with untreated groups. It was therefore hypothesized that mmu-miR-96 may affect the process of decidualization through a specific mechanism. In order to investigate this hypothesis, the biological functions of mmu-miR-96 were examined at the cellular level. Upregulation of mmu-miR-96 promoted stromal and decidual cell apoptosis, which is a vital molecular event for stromal cell decidualization, and which is a key factor for successful implantation. Boeddeker and Hess (33) indicated that apoptosis served a major role in the female reproductive tract with regards to different requirements throughout the menstrual cycle, including decidualization and implantation, or menstrual shedding of the non-pregnant endometrium. Therefore, increased apoptosis of stromal cells may have an effect on decidualization and implantation.

mmu-miR-96 may function by reverse regulating its target genes. Chen et al (11) revealed a regulatory relationship between miRNAs and mRNAs, and discovered that the miRNAs mmu-miR-96 and mmu-miR-200b target the anti-apoptotic protein $\mathrm{Bcl} 2$, as well as Kruppel-like factor 13. Correia-da-Silva et al (34) investigated the spatial and temporal pattern of expression of the $\mathrm{Bcl} 2$ family members in uterine tissues at the IS, from the post-implantation period to parturition, and demonstrated that the apoptotic mitochondrion-dependent pathway is involved in decidual regression during pregnancy progression. Joswig et al (35) confirmed the presence of $\mathrm{Bcl} 2$-associated $\mathrm{X}$ protein and $\mathrm{Bcl} 2$ in mouse decidua, and indicated that both were absent in the uterine epithelium. These findings suggested that $\mathrm{Bcl} 2$ has an important role in this process. The present study used computational analysis to predict potential mmu-miR-96 target sequences and found three potential anti-apoptosis-related gene targets: $\mathrm{Bcl} 2, \mathrm{Bcl} 2112$ and $\mathrm{Bcl} 2113$. The results demonstrated that $\mathrm{Bcl} 2$ expression was higher at IIS compared with at IS on day 5 of pregnancy through DGE analysis, and this result is inverse to the expression pattern of mmu-miR-96 on the same day of pregnancy. In addition, $\mathrm{Bcl} 2$ protein expression was inhibited following the upregulation of mmu-miR-96. Finally, a Bcl2-fluorescent reporter assay was used to further confirm that $\mathrm{Bcl} 2$ is indeed a target gene of mmu-miR-96.

In conclusion, the present study indicated that mmu-miR-96 affects the apoptosis of stromal cells and decidual cells via regulation of $\mathrm{Bcl} 2$, a process that is important in the establishment and maintenance of pregnancy. The mechanism of mmu-miR-96 participation in embryonic implantation should be investigated in greater detail in future studies.

\section{Acknowledgments}

The present study was supported by the National Natural Science Foundation of China (grant no. 31501207) and by the Science and Technology Commission of Chongqing, Chongqing, China [grant no. SCXK (YU) 2012-0001].

\section{References}

1. Cha J, Sun X and Dey SK: Mechanisms of implantation: Strategies for successful pregnancy. Nat Med 18: 1754-1767, 2012.

2. Wang $\mathrm{H}$ and Dey SK: Roadmap to embryo implantation: Clues from mouse models. Nat Rev Genet 7: 185-199, 2006.

3. Parkes AS: The Functions of the Corpus Luteum. II.-The Experimental Production of Placentomata in the Mouse. Proceedings of the Royal Society of London Series B, Containing Papers of a Biological Character 104: 183-188, 1929.

4. Shimizu A, Maruyama T, Tamaki K, Uchida H, Asada H and Yoshimura Y: Impairment of decidualization in SRC-deficient mice. Biol Reprod 73: 1219-1227, 2005.

5. Eyal O, Jomain JB, Kessler C, Goffin V and Handwerger S: Autocrine prolactin inhibits human uterine decidualization: A novel role for prolactin. Biol Reprod 76: 777-783, 2007.

6. Chakrabarty A, Tranguch S, Daikoku T, Jensen K, Furneaux H and Dey SK: MicroRNA regulation of cyclooxygenase-2 during embryo implantation. Proc Natl Acad Sci USA 104: 15144-15149, 2007.

7. Hu SJ, Ren G, Liu JL, Zhao ZA, Yu YS, Su RW, Ma XH, Ni H, Lei $\mathrm{W}$ and Yang ZM: MicroRNA expression and regulation in mouse uterus during embryo implantation. J Biol Chem 283: 23473-23484, 2008.

8. Shen LJ, He JL, Yang DH, Ding YB, Chen XM, Geng YQ, Liu SJ, Liu XQ and Wang YX: Mmu-microRNA-200a overexpression leads to implantation defect by targeting phosphatase and tensin homolog in mouse uterus. Reprod Sci 20: 1518-1528, 2013.

9. Singh SK, Pal Bhadra M, Girschick HJ and Bhadra U: MicroRNAs-micro in size but macro in function. FEBS J 275: 4929-4944, 2008.

10. Zhao Y and Srivastava D: A developmental view of microRNA function. Trends Biochem Sci 32: 189-197, 2007.

11. Chen K, Chen X, He J, Ding Y, Geng Y, Liu S, Liu X and Wang Y: Mouse endometrium temporal and spatial expression mRNA and microRNA associated with embryo implantation. Reprod Sci 22: 1399-1408, 2015.

12. Han Y, Chen J, Zhao X, Liang C, Wang Y, Sun L, Jiang Z, Zhang Z, Yang R, Chen J, et al: MicroRNA expression signatures of bladder cancer revealed by deep sequencing. PLoS One 6: e18286, 2011.

13. Yamada Y, Enokida H, Kojima S, Kawakami K, Chiyomaru T, Tatarano S, Yoshino H, Kawahara K, Nishiyama K, Seki N and Nakagawa M: MiR-96 and miR-183 detection in urine serve as potential tumor markers of urothelial carcinoma: Correlation with stage and grade, and comparison with urinary cytology. Cancer Sci 102: 522-529, 2011.

14. Nymark P, Guled M, Borze I, Faisal A, Lahti L, Salmenkivi K, Kettunen E, Anttila S and Knuutila S: Integrative analysis of microRNA, mRNA and aCGH data reveals asbestos- and histology-related changes in lung cancer. Genes Chromosomes Cancer 50: 585-597, 2011. 
15. Lin H, Dai T, Xiong H, Zhao X, Chen X, Yu C, Li J, Wang X and Song L: Unregulated miR-96 induces cell proliferation in human breast cancer by downregulating transcriptional factor FOXO3a. PLoS One 5: e15797, 2010.

16. Myatt SS, Wang J, Monteiro LJ, Christian M, Ho KK, Fusi L, Dina RE, Brosens JJ, Ghaem-Maghami S and Lam EW: Definition of microRNAs that repress expression of the tumor suppressor gene FOXO1 in endometrial cancer. Cancer Res 70: 367-377, 2010.

17. Pineau P, Volinia S, McJunkin K, Marchio A, Battiston C, Terris B, Mazzaferro V, Lowe SW, Croce CM and Dejean A: miR-221 overexpression contributes to liver tumorigenesis. Proc Natl Acad Sci USA 107: 264-269, 2010.

18. Guo Y, Liu H, Zhang H, Shang C and Song Y: miR-96 regulates FOXO1-mediated cell apoptosis in bladder cancer. Oncol Lett 4 $561-565,2012$.

19. Guttilla IK and White BA: Coordinate regulation of FOXO1 by miR-27a, miR-96, and miR-182 in breast cancer cells. J Biol Chem 284: 23204-23216, 2009.

20. Li J, Li P, Chen T, Gao G, Chen X, Du Y, Zhang R, Yang R, Zhao W, Dun S, et al: Expression of microRNA-96 and its potential functions by targeting FOXO3 in non-small cell lung cancer. Tumour Biol 36: 685-692, 2014.

21. Ma XH, Hu SJ, Ni H, Zhao YC, Tian Z, Liu JL, Ren G, Liang XH, Yu H, Wan P and Yang ZM: Serial analysis of gene expression in mouse uterus at the implantation site. J Biol Chem 281: 9351-9360, 2006.

22. Tan Y, Li M, Cox S, Davis MK, Tawfik O, Paria BC and Das SK: HB-EGF directs stromal cell polyploidy and decidualization via cyclin D3 during implantation. Dev Biol 265: 181-195, 2004

23. Liao XG, Li YL, Gao RF, Geng YQ, Chen XM, Liu XQ, Ding YB, $\mathrm{Mu}$ XY, Wang YX and He JL: Folate deficiency decreases apoptosis of endometrium decidual cells in pregnant mice via the mitochondrial pathway. Nutrients 7: 1916-1932, 2015.

24. Li Q, Kannan A, Wang W, Demayo FJ, Taylor RN, Bagchi MK and Bagchi IC: Bone morphogenetic protein 2 functions via a conserved signaling pathway involving Wnt 4 to regulate uterine decidualization in the mouse and the human. J Biol Chem 282: 31725-31732, 2007.
25. Liang XH, Zhao ZA, Deng WB, Tian Z, Lei W, Xu X, Zhang XH, Su RW and Yang ZM: Estrogen regulates amiloride-binding protein 1 through CCAAT/enhancer-binding protein-beta in mouse uterus during embryo implantation and decidualization. Endocrinology 151: 5007-5016, 2010.

26. Livak KJ and Schmittgen TD: Analysis of relative gene expression data using real-time quantitative PCR and the 2(-Delta Delta C(T)) Method. Methods 25: 402-408, 2001.

27. $\mathrm{Wu} \mathrm{R}$, Tang $\mathrm{S}$, Wang $\mathrm{M}, \mathrm{Xu} \mathrm{X}$, Yao $\mathrm{C}$ and Wang $\mathrm{S}$ : MicroRNA-497 induces apoptosis and suppresses proliferation via the Bcl-2/Bax-Caspase9-caspase3 pathway and cyclin D2 protein in HUVECs. PLoS One 11: e0167052, 2016.

28. Liu Z, Jiang R, Yuan S, Wang N, Feng Y, Hu G, Zhu X, Huang K, $\mathrm{Ma}, \mathrm{Xu} \mathrm{G}$, et al: Integrated analysis of DNA methylation and RNA transcriptome during in vitro differentiation of human pluripotent stem cells into retinal pigment epithelial cells. PLoS One 9: e91416, 2014

29. Fouladi Nashta AA, Andreu CV, Nijjar N, Heath JK and Kimber SJ: Role of leukemia inhibitor factor (LIF) in decidualisation of murine uterine stromal cells in vitro. J Endocrinol 181: 477-492, 2004

30. Evans MJ and Kaufman MH: Establishment in culture of pluripotential cells from mouse embryos. Nature 292: 154-156, 1981.

31. Estella C, Herrer I, Moreno-Moya JM, Quiñonero A, Martínez S, Pellicer A and Simón C: miRNA signature and Dicer requirement during human endometrial stromal decidualization in vitro. PLoS One 7: e41080, 2012.

32. Zhang Q, Zhang H, Jiang Y, Xue B, Diao Z, Ding L, Zhen X, Sun H, Yan G and Hu Y: MicroRNA-181a is involved in the regulation of human endometrial stromal cell decidualization by inhibiting Kruppel-like factor 12. Reprod Biol Endocrinol 13: 23, 2015.

33. Boeddeker SJ and Hess AP: The role of apoptosis in human embryo implantation. J Reprod Immunol 108: 114-122, 2015.

34. Correia-da-Silva G, Bell SC, Pringle JH and Teixeira NA: Patterns of expression of Bax, Bcl-2 and Bcl-x(L) in the implantation site in rat during pregnancy. Placenta 26: 796-806, 2005.

35. Joswig A, Gabriel HD, Kibschull $M$ and Winterhager E: Apoptosis in uterine epithelium and decidua in response to implantation: Evidence for two different pathways. Reprod Biol Endocrinol 1: 44, 2003. 